\title{
Abbreviations and Note on the Texts
}

Abbreviations cited parenthetically in the text refer to the following works by Edward Dorn:

BS By the Sound (Mount Vernon, Wash.: Frontier Press, I97I)

CP The Collected Poems, 1956-1974 (Bolinas, Calif.: Four Seasons Foundation, 1975)

HLJ Hello, La Jolla (Berkeley: Wingbow Press, 1978)

I Interviews, ed. Donald Allen (Bolinas, Calif.: Four Seasons Foundation, 1980)

RGA Recollections of Gran Apachería (San Francisco: Turtle Island Foundation, 1974)

$S$ Slinger (Berkeley: Wingbow Press, 1975)

SB Some Business Recently Transacted in the White World (West Newbury, Mass.: Frontier Press, 197 I)

SH The Shoshoneans: The People of the Basin Plateau (New York: William Morrow, I 966)

SL "Strumming Language," in Anne Waldman and Marilyn Webb, eds., Talking Poetics from Naropa Institute: Annals of the Jack Kerouac School of Disembodied Poetics, vol. I (Boulder, Colo.: Shambala, 1 975), 83-95 
V Views, ed. Donald Allen (San Francisco: Four Seasons Foundation, 1980)

YL Yellow Lola, Formerly Titled Japanese Neon (Hello, La Jolla, Book II) (Santa Barbara, Calif.: Cadmus Editions, I 98 I)

We have observed Dorn's occasionally idiosyncratic spelling and typographic conventions throughout. All references to Slinger are to the unpaginated Wingbow edition, which we have paginated, beginning with page $I$ on the first part title, "Book I." 